\title{
Crying and sadness after sexual intercourse: a qualitative study of postcoital dysphoria
}

\author{
Magdalena Liberacka-Dwojak, Helena Ostrowicka, Paweł Izdebski \\ Kazimierz Wielki University in Bydgoszcz, Poland
}

\begin{abstract}
A phenomenon of postcoital dysphoria is the experience of negative effect after sexual intercourse, specifically tearfulness, a sense of melancholy or depression, anxiety, or aggression, which is hard to control or minimalize. The causes of this phenomenon are unknown. This article presents a content analysis of personal descriptions published on online forums from women suffering from postcoital dysphoria. The study aimed to determine the problem of this phenomenon in personal experiences, to exhibit if psychological description coincides with women's descriptions, and to check how often women write on forums about their problem. The study was qualitative research: the content analysis of posts appearing on online forums. The study included six online forums related to mental health, relationship and sexuality. All descriptions have been divided into three groups connected with emotions, behaviour, and partner's response. Due to the qualitative research, the most popular PCD symptoms are crying and sobbing what might result from both positive and negative emotions. Based on the theoretical description of PCD symptoms do not coincide with personal experiences. Furthermore, the partner's response is relevant for understanding and coping with sexual difficulties symptoms. The postcoital dysphoria causes remain multifactorial.
\end{abstract}

Key words: postcoital dysphoria, sexual difficulties, qualitative research

Seksuologia Polska 2021; 19

\section{Introduction}

Sexual dysfunctions among women relate to desire, arousal, orgasm, or pain, which occur before or during sexual activities [1]. They may have existed for their entire adult life or have occurred after a period of normal functioning. Moreover, the dysfunctions may be generalized or happen only in certain situations. One of the most important criteria is that sexual dysfunction causes significant distress or interpersonal difficulties. In developing sexual dysfunctions several factors take part: neurological and biological (e.g. illness, surgery, medications, ageing), psychological (e.g. attitudes toward sex, early negative conditioning experiences, sexual trauma) and social (e.g. conflicts, communication, dislikes) factors [2].

Adres do korespondencji: Magdalena Liberacka-Dwojak Kazimierz Wielki University in Bydgoszcz, Poland e-mail: li.magda@wp.pl

Przyjęto: 2.10 .2020 Zaakceptowano: 16.03.202
Unfortunately, little attention has been given to emotional problems occurring post-coitally. Postcoital dysphoria (PCD) is the experience of negative affect after sexual intercourse. Specifically speaking, tearfulness, a sense of melancholy or depression, anxiety or aggression can appear [1]. The dysphoria can last for over an hour, and it is hard for a partner or individual to control or minimalize [3]. The causes of this phenomenon are unknown, but probably they are multifactorial, mostly with a contribution of psychological factors. According to Basson's model [2], not only physical pleasure is important for women, but also intimacy with their partner, so it is possible that also attachment plays a great role in those symptoms [1]. Postcoital dysphoria can be associated with distress, sexual abuse, or sexual dysfunctions [4]. PCD is also related to hormonal changes during sexual intercourse, specifically in the endocrine system, which can cause sadness or a sense of depression. Women who suffer from postnatal depression are also at risk of having postcoital dysphoria, which confirms hormonal 
fluctuations as a mechanism of understanding these symptoms [5]. Not only psychological or biological factors lead to PCD but also physical pain. For those, who suffer from dyspareunia or vaginismus, PCD symptoms can be a response to pain [3]. In men, this phenomenon occurs also as an auto-immune response to semen or sexual beliefs [6].

It has been mostly reported among females [7]. Bird et al. [3] reported that $32.9 \%$ of women had experienced postcoital dysphoria. Experiencing sadness or tearfulness after sexual intercourse may lead to reducing the desire for sexual activities or even aroiding them.

It is relevant to underline, that there is a limited number of research about postcoital dysphoria conducted by specialists. Nevertheless, an internet search identifies a significant number of personal experiences described by individuals. It confirms that PCD symptoms exist and are important for many women and their partners.

\section{Internet forums}

The Internet allows people to share information via forums, chat rooms, or blogs [7]. The most important aspect of using them is that individuals can benefit from getting support from other people with the same difficulties [8]. This support includes informational, emotional, instrumental, and appraisal factors, which give motivation or encouragement [7].

Forums allow participants to get information related to their problem: they receive motivation, discuss the same goals, experiences. Moreover, members can read about personal struggles with overcoming problems. They take responsibility for each other, standing by their goals and what is also relevant, they can laugh at themselves, which helps in overcoming difficulties. Moreover, people can communicate without judgment, staying anonymous [7]. It may also be facilitation for individuals, who are socially isolated, ashamed, or geographically dispersed, but are nevertheless seeking help. The Internet has been held as a safe place for many societies, where users can raise a discussion which they would not do face-to-face, which can be defined as a self-help category [9, 10]. Furthermore, online support via forums or blogs can bring education for participants with the same issue, which con lead to normalizing illness or reducing stigma [8].

\section{Material and methods}

\section{Research questions}

This study attempted to describe the problem of po- stcoital dysphoria as described by women. The authors were interested in investigating how often women write on online forums about their problem and what phrases they use to describe their experiences. Moreover, it was attempted to ascertain whether the theory-based phenomenon of postcoital dysphoria is coherent with personal descriptions of its symptoms.

\section{Method}

A qualitative and quantitative method of research was chosen to elucidate research questions. The aim of the qualitative methods in the psychology field is to investigate the background of a phenomenon and understand human behaviour. They help answer why and how questions [11]. More specifically, content analysis is one of the most widely used qualitative techniques. It is defined as a method for studying documents and communication [12]. It is used to describe a phenomenon, containing an emotional sphere [13]. There are four factors necessary for content analysis: being objective, systematic, explicit, and clear [14]. The content analysis consists of six steps: the selection of research material; multiple readings of chosen texts; coding, grouping, and categorization; defining the categories; building tables with quotations and creating a model. This method may be used with qualitative or quantitative data [12].

\section{Selection of empirical materials}

Forums that have been included in quantitative research:

Forums that have been included in qualitative research: quora.com, forum.bodybuilding.com, psychforums.com, elitepartner.de, netkobiety.pl, wizaz.pl, all connected with motivation, mental health, relationships, and sexuality.

Only forums with the highest number of posts during the most recent years were included in qualitative research, with posts referring only to emotions, behaviour, and partner responses.

\section{Results}

It is relevant to point out how often women write about their problem. No comments were included in the analysis, only main posts.

The first sign of this phenomenon was found in 2001. The results show that the postcoital dysphoria phenomenon is a more and more frequently raised topic.

Women's descriptions of this phenomenon have been included in three categories:

1. Emotions - all mental states which refer to pleasure or displeasure, 
Table 1. Selection of forums

\begin{tabular}{lll}
\hline English sites & 1. Psychforum.com & 11. Theattractionforum.com \\
2. Bodybuilding.com & 12. Citydata.com \\
3. Thetfp.com & 13. Babyandbump.com \\
4. Huggies.com & 14. Netmums.com \\
5. Rsdnation.com & 15. Rooshuforum.com \\
6. Suave.com & 16. Self.com \\
7. Mpuaforum.com & 17. Quora.com \\
8. Citydata.com & 18. Menshealth.com \\
9. Thenakedscientists.com & 19. Reddit.com \\
10. Mazewomenshealth.com & 20. Thestudentroom.co.uk \\
1. Elitepartner.com & 6. Desired.de \\
2. Gofeminin.de & 7. Onmedia.de \\
3. Befriends.begritte.de & 8. Pickupforum.de \\
4. Netdoktor.at & 9. Kleiderkreisel.de \\
5. Psychotherapistpraxis.at & & \\
& &
\end{tabular}

${ }^{1}$ Key words and phrases chosen in German and Polish: weinen nach dem Sex, schlechtes Gefühl nach dem Sex, płacz po seksie, smutek po seksie

2. Behaviour - all actions made by women which refer to their emotions and feelings during or after sexual intercourse,

3. Partner's response - partner's reactions to presented behaviour. It is defined by specific questions, behaviour, or by an attempt to comfort their partner. Description of phenomenon by women

\section{Emotions}

Women describe postcoital dysphoria symptoms as strong, overwhelming feelings. Mostly it relates to pleasure, love, attachment, and the need to release emotions. Less often symptoms appear as an effect of frustration or displeasure.

Sometimes I have cried when I needed to release emotions and wasn't aware of it [...]. I felt totally open to expressing my emotions and to release whatever was bothering me. It's very cathartic for me when I have a lot on my plate.

It's a horrible thing for a woman to do to a man unless it occurs because of love/overwhelming feelings, and it's fully explained to him so he understands it's a good thing/he has moved you emotionally in a good way.

I cry during sex, but it's because it's so intense and feels so freaking good. I can't control it. When it feels good, I cry.

Never personally but I do get a huge emotional release and can totally understand women who cry afterwards, it is just a physical sign of being completely overwhelmed by emotion.
Table 2. The number of posts regarding postcoital dysphoria

$\begin{array}{cccc}2001 & 1 & 2011 & 8 \\ 2002 & 1 & 2012 & 12 \\ 2003 & 1 & 2013 & 9 \\ 2004 & 4 & 2014 & 11 \\ 2005 & 3 & 2015 & 5 \\ 2006 & 3 & 2016 & 9 \\ 2007 & 9 & 2017 & 10 \\ 2008 & 9 & 2018 & 15 \\ 2009 & 15 & & \\ 2010 & 9 & & \end{array}$

It happens to me too. If I have lots of stress at work then after good sex I start to relax and cry. That's my body response (translation).

[...] Having sex and being intimate is extremely vulnerable. I've cried with partners that I was in love with $[\ldots . .$.

I had something like that once when I felt very good. But it resulted from many factors, more from humour and attachment to my partner, so that I want to be with him and I feel good with him, that we are a long-time together and it was connected with our future plans (translation).

It is relevant to underline that postcoital dysphoria symptoms can appear also as a response to negative feelings or pain. 
I suffer from vaginismus, a condition where penetrative intercourse is painful. I was having sex with my boyfriend and experiencing pain and discomfort when I started crying. Not from the physical pain, but from the complications and frustrations that came along with the experience that was supposed to be magical and pleasant. While my partner was experiencing those very feelings, I was simultaneously conflicted, in pain, and unhappy. I couldn't help killing the mood with some tears.

\section{Behaviour}

Women describe the most frequent/common PCD symptoms as tearfulness, crying, sobbing, or bursting into tears. None of them describes aggression or anxiety.

[...] However, oftentimes post-orgasm I feel very emotional and often tear up or cry for no apparent reason [...].

I never cry after sex, but I will often sob for a few moments during sex. It's at that moment when I'm reaching a higher pleasure zone - the one right below orgasm. It's so intense that it will bring tears to my eyes, and especially if I can't orgasm as soon as humanly possible at that point, I'll sob vocally as well.

I burst into tears, and not from pain [...].

[...] I was having sex with my boyfriend and experiencing pain and discomfort when I started crying [...].

\section{Partner's response}

Another relevant topic that appears in women's descriptions of postcoital dysphoria is their partner's response. Some of the partners were unsure or scared about the situation. Most partners try to comfort women by hugging them or asking about their feelings.

[...] It was a strange feeling, and I was shocked by my own tears. My boyfriend immediately wrapped me in his arms and asked if I was OK.

[...] He would just keep asking me what was wrong, and I wouldn't know. He would just hold me, but I couldn't really be comfortable. [...]

Man asked: "Why are you crying?". Woman said: "I don't know".

My partner asked me unsurely what happened. (translation).
He asked me what happened, and I only said that "everything is ok" (translation).

My partner got used to it, but at first, he didn't understand it (translation).

I felt something like that a few times and my boyfriend got scared (translation).

My partner always laughs and says: „don't cry, it wasn't so bad" and then hugs me and kisses me (translation).

\section{Based-on theory and personal description of postcoital dysphoria}

It is relevant to underline differences in based-on theory and personal description of postcoital dysphoria. Only keywords that describe emotions or behaviour were selected from the texts. Then a table with quotes was created.

As presented above, the description of personal experiences does not coincide with the based-on theory description of postcoital dysphoria. Psychology concentrates only on the negative effect after sexual intercourse, precisely speaking tearfulness, melancholy, anxiety, or aggression. Personal experiences also contain such feelings as feeling intense, overwhelming emotions, the need to release emotions, or feeling attachment. In women's experiences crying and being sad is only a response to stronger and more intense emotions and feeling close to their partner. Both descriptions contain behaviour that is hard to control.

\section{Discussion}

Quantitative research shows that women probably have become more open or courageous in writing about sexual difficulties. This may result from the fact that the global network allows people to stay anonymous or to share information with people experiencing the same difficulties. Moreover, the Internet has become more and more popular during the last decade [7, 8]. Furthermore, research shows that our culture has witnessed cultural and social movements since the sexual revolution in the early $20^{\text {th }}$ century [15]. Women often experience the desire to communicate about their problems: they feel comfortable discussing sexual matters [16].

Table 3. Comparison of based-on theory and personal description of PCD symptoms

- Negative effect after sexual intercourse,

- tearfulness,

- sense of melancholy,

- sense of depression,

- anxiety,

- aggression,

- hard to control or minimalize.
- Crying, sadness,

- feel very emotional, overwhelming emotions, express emotions, intense emotions (feeling intimacy), emotional release,

- need to release emotions,

- attachment,

- frustration, unhappiness,

- hard to control. 
Personal experiences and the psychological theory of postcoital dysphoria

Psychological theory concentrates only on negative effects after sexual intercourse, which are hard to control or minimalize, without emotions experienced before or during sexual activity, or the causes of the appearance of these symptoms.

Personal experiences include not only negative emotions like sadness, a sense of depression, and frustration, but also underline the role of strong emotions. Women describe it as intense emotions and intimacy when they are overcome with emotions. It contributes to the need to release these emotions which manifest themselves in crying or feeling sad. Moreover, women also talk about a strong sense of self-loathing or shame due to their behaviour.

Emotional closeness, sexual stimuli, and relationship satisfaction play an important role in sexual intercourse. According to Basson's model [2], the most important factors, which take part in the motivation to have sex are emotional intimacy, physical pleasure, and expressing love and attraction. It refers to surroundings, whereas a relationship characterized by trust, emotions, and flirting is increasing the strength of sexual response [17], which coincides with women's description of feeling overcome with emotions, like intimacy, happiness, closeness to a partner.

\section{Women's descriptions of postcoital dysphoria}

\section{Emotions}

Women often talk about intense emotions and the need to release them. They underline that crying might result from feeling pleasure and comfort. Felt emotions are so intense and overwhelming that they are hard to control. Furthermore, it might result from the need to release problems, difficulties, or things that bothered the women during the day. Sexual intercourse with a loving partner makes them feel open, comfortable, and relaxed so that expressing emotions is easier. Crying after sexual activity might also result from an impression of intimacy and attachment. It confirms that the sexual response cycle [17] clarifies the phenomenon of postcoital dysphoria. It is relevant to underline that crying after sexual intercourse results not only from positive emotions but also from pain or displeasure. Some women underline the role of frustration and feeling unhappy. It pertains to emotions during or after crying.

\section{Behaviour}

It is relevant to underline what behaviours women present most often and if it coincides with the based-on theory description. As presented above from the women's description we can see that crying, sobbing, and bursting into tears are the most common PCD symptoms. This partly coincides with the psychological description of postcoital dysphoria.

\section{Partner's response}

It is relevant to underline the partner's role and response in experiencing postcoital dysphoria symptoms. According to the women's descriptions, their partners mostly ask what is wrong, try to comfort them, and minimalize crying by hugging or kissing. It is also very common that men are unsure, they do not realize what is wrong. Support from a partner might play a key role in women's difficulties. Moreover, the perception of support is related to greater satisfaction [18]. According to Granero-Molina et al. [19]. women are searching for understanding in socio-family support. Perhaps the partner's response is relevant in further understanding and coping with PCD syndrome.

\section{Seeking help}

Women writing on forums are also seeking help. They are trying to find someone with similar difficulties with whom to share information and support, what is relevant in overcoming problems and coping with them - feeling that one is not alone. In this case, internet forums can be very helpful, because they are anonymous and available for most people. Furthermore, some women are worried as to whether they are normal. Perhaps it may result from the fact that there is a limited amount of information about postcoital dysphoria. It contributes to a lack of knowledge and education about sexual dysfunctions, which might bring negative emotions, misapprehension, or insecurity when sexual functioning is disturbed.

\section{Positive or negative emotions?}

According to the psychological description, the causes of this phenomenon are multifactorial. It might be associated with distress, sexual dysfunctions, hormonal changes during sexual intercourse, pain, or psychological factors [4-6]. The reading of multiple chosen texts has verified that in personal experiences there are two main factors for feeling sad and crying:

1. Positive emotions, like feeling overcome with emotions, intense emotions, intimacy, happiness, attachment. For many women feeling so close to their partner during sexual intercourse makes them feel relaxed, comfortable, and pleasant causing them to cry.

2. Negative emotions, like frustration or pain. For those who suffer from pain, PCD symptoms can be a response to pain. 


\section{Postcoital dysphoria as a disorder or natural phenomenon?}

The noticeable presence of the theme of PCD on online forums indicates that problems related to women's sexuality have been introduced into the public space. From the perspective of the feminist paradigm [20], this phenomenon could be interpreted in the categories of women clamouring for a voice in matters that concern them. As this research has shown, this voice is not synonymous with theoretical knowledge about postcoital dysphoria. Women's experiences are described as positive emotions and behaviours, which highlight the normalization process of PCD, simultaneously questioning the classification of this state as sexual dysfunction. Basson's Model, adopted by Koslyn and Rosenberg [2], emphasizes the importance of gender in understanding and explaining differences in sexual experiences. In the context of the data obtained in our research, the question arises of whether the concentration of PCD theory on negative states and their consequences for women is not the result of treating what is male as a norm. Concerning this norm, women's behaviours are presented as a disorder or deviation. The affirmative answer to this question would also mean that the pejoratively connected connotations with PCD only strengthen the centuries-old myth of the female being (over) sensitive and weak.

In some cases, postcoital dysphoria is understood as a disorder. Sexual dysfunctions are a heterogeneous group of disorders that are typically characterized by a clinically significant disturbance in a person's ability to respond sexually or to experience sexual pleasure. If severe relationship distress, partner violence, or significant stressors better explain the sexual difficulties, then a sexual dysfunction diagnosis is not made, but an appropriate $\mathrm{V}$ or $\mathrm{Z}$ code may be listed. In many cases, a precise etiological relationship between another condition and sexual dysfunction cannot be established [21].

Regarding personal descriptions of PCD symptoms, crying and feeling sad after sexual intercourse does not always contribute to a disturbance in the ability to respond sexually or experience pleasure. On the contrary, these symptoms often appear as a response to pleasure. Still, the aetiology of this phenomenon remains unknown. Nevertheless, postcoital dysphoria might appear as a response to pain or distress which contributes to significant distress. Postcoital dysphoria should not be always operationalized as a mental disorder. While making a diagnosis, the causes of this phenomenon should be taken into consideration, which should be a key to diagnosing postcoital dysphoria as a mental disorder with an appropriate $\mathrm{V}$ or $\mathrm{Z}$ code because of possible disturbance in a person's ability to respond sexually.

\section{Conclusions}

1. Based-on theory description of PCD symptoms does not coincide with personal experiences. The first one concentrates only on negative affect after sexual intercourse, not including feeling intense and overwhelming emotions.

2. Postcoital dysphoria symptoms con result from both positive and negative emotions, whereas the most common behaviours in personal experiences are crying, sobbing, and bursting into tears.

3. Portner's responses include trying to comfort their partners, but they are often also unsure and scared. Positive response and support might help cope with difficulties.

4. Postcoital dysphoria causes might be explained by the sexual response cycle, which relates to emotional intimacy and expressing love as factors taking part in motivation to sexual intercourse.

\section{References:}

1. Schweitzer RD, O'Brien J, Burri A. Postcoital Dysphoria: Prevalence and Psychological Correlates. Sex Med. 2015; 3(4): 235-243, doi: 10.1002/sm2.74, indexed in Pubmed: 26797056.

2. Kosslyn MS, Rosenberg RS. Introducing psychology. Brain, Person, Group 2010: 495-515.

3. Bird B, Schweitzer R, Strassberg D. The Prevalence and Correlates of Postcoital Dysphoria in Women. J Sex Health. 2011; 23(1): 14-25, doi: 10.1080/19317611.2010.509689.

4. Maczkowiack J, Schweitzer RD. Postcoital Dysphoria: Prevalence and Correlates Among Males. J Sex Marital Ther. 2019; 45(2): 128-140, doi: 10.1080/0092623X.2018.1488326, indexed in Pubmed: 30040588.

5. Mehta D, Schweitzer RD, Maczkowiack J. Overlap of Postnatal Depression and Postcoital Dysphoria in Women- Implications for Common Underlying Mechanisms. Journal of Depression and Anxiety. 2017; s12, doi: 10.4172/2167-1044.s12-002.

6. Serefoglu EC. Post-Orgasmic Illness Syndrome: Where Are We? J Sex Med. 2017; 14(5): 641-642, doi: 10.1016/j. jsxm.2017.03.250, indexed in Pubmed: 28499517.

7. Hwang KO, Ottenbacher AJ, Green AP, et al. Social support in an Internet weight loss community. Int J Med Inform. 2010; 79(1): 5-13, doi: 10.1016/j.ijmedinf.2009.10.003, indexed in Pubmed: 19945338.

8. Moore D, Ayers S. Virtual voices: social support and stigma in postnatal mental illness Internet forums. Psychol Health Med. 2017; 22(5): 546-551, doi: 10.1080/13548506.2016.1189580, indexed in Pubmed: 27218265.

9. Seale C, Charteris-Black J, MacFarlane A, et al. Interviews and internet forums: a comparison of two sources of qualitative data. Qual Health Res. 2010; 20(5): 595-606, doi: 10.1177/1049732309354094, indexed in Pubmed: 20008955.

10. Davison K, Pennebaker J, Dickerson S. Who talks? The social psychology of illness support groups. American Psychologist. 2000; 55(2): 205-217, doi: 10.1037/0003-066x.55.2.205.

11. Given L. Q Methodology. The Sage Encylopedia of Qualitative Research Methods. SAGE Publications 2008. 
12. Elo $\mathrm{S}$, Kyngäs $\mathrm{H}$. The qualitative content analysis process. J Adv Nurs. 2008; 62(1): 107-115, doi: 10.1111/j. 1365-2648.2007.04569.x, indexed in Pubmed: 18352969.

13. Hsieh HF, Shannon SE. Three approaches to qualitative content analysis. Qual Health Res. 2005; 15(9): 1277-1288, doi: 10.1177/1049732305276687, indexed in Pubmed: 16204405.

14. Franzosi R. Content Analysis: Objective, Systematic and Quantitative. In: From Words to Numbers: narrative, data and social science. Cambridge University Press, Cambridge 2004: 32-35.

15. Sigusch $\mathrm{V}$. On cultural transformations of sexuality and gender in recent decades. Ger Med Sci. 2004; 2: 1-14.

16. Eldridge KF, Giraldi A. Communication About Sexual Matters With Women Attending a Danish Fertility Clinic: A Descriptive Study. Sex Med. 2017; 5(3): e196-e202, doi: 10.1016/j. esxm.2017.06.005, indexed in Pubmed: 28823315.
17. Basson R, Basson R. The female sexual response: a different model. J Sex Marital Ther. 2000; 26(1): 51-65, doi: 10.1080/009262300278641, indexed in Pubmed: 10693116.

18. Kinsinger SW, Laurenceau JP, Carver CS, et al. Perceived partner support and psychosexual adjustment to breast cancer. Psychol Health. 2011; 26(12): 1571-1588, doi: 10.1080/08870446.2010.533771, indexed in Pubmed: 21598184.

19. Granero-Molina J, Matarín Jiménez TM, Ramos Rodríguez $C$, et al. Social Support for Female Sexual Dysfunction in Fibromyalgia. Clin Nurs Res. 2018; 27(3): 296-314, doi: 10.1177/1054773816676941, indexed in Pubmed: 29421939.

20. Butler J. Gender trouble: feminism and the subversion of identity. Routledge, London 1990.

21. American Psychiatric Association. Sexual dysfunctions. In: Diagnostic and statistical manual of mental disorders 5th ed. 2013. 